\title{
REVISED Case Report: Double lumen tube insertion in a morbidly obese patient through the non-channelled blade of the King
}

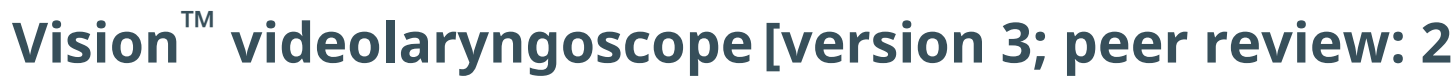

\section{approved]}

\author{
Mohamed El-Tahan1, D. John Doyle², Alaa M Khidr ${ }^{1}$, Ahmed G Hassieb \\ 1Department of Anesthesiology, King Fahd Hospital, Dammam University, Al Khubar, 31952, Saudi Arabia \\ 2Department of General Anesthesiology, Cleveland Clinic, Cleveland, OH, 44195, USA
}

\begin{tabular}{l}
\hline V3 First published: 17 Jun 2014, 3:129 \\
https://doi.org/10.12688/f1000research.4481.1 \\
Second version: 18 Jul 2014, 3:129 \\
https://doi.org/10.12688/f1000research.4481.2 \\
Third version: 08 Aug 2014, 3:129 \\
https://doi.org/10.12688/f1000research.4481.3 \\
Latest published: 29 Sep 2014, 3:129 \\
https://doi.org/10.12688/f1000research.4481.4 \\
\hline
\end{tabular}

\section{Abstract}

We describe the insertion of the double lumen endobronchial tube (DLT) using a non-channeled standard blade of the King Vision ${ }^{\mathrm{TM}}$ videolaryngoscope for one lung ventilation (OLV) in a morbidly obese patient with a predicted difficult airway, severe restrictive pulmonary function, asthma, and hypertension. The patient was scheduled for a video-assisted thoracoscopic lung biopsy. The stylet of the DLT was bent to fit the natural curve of the \#3 non-channeled blade of the King Vision $^{\mathrm{TM}}$ videolaryngoscope. We conclude that the use of King Vision $^{\mathrm{TM}}$ videolaryngoscope could offer an effective method of DLT placement for OLV.

\section{Keywords}

one lung ventilation; difficult intubation; double lumen tube; King Vision $^{\mathrm{TM}}$ videolaryngoscope; thoracic surgery

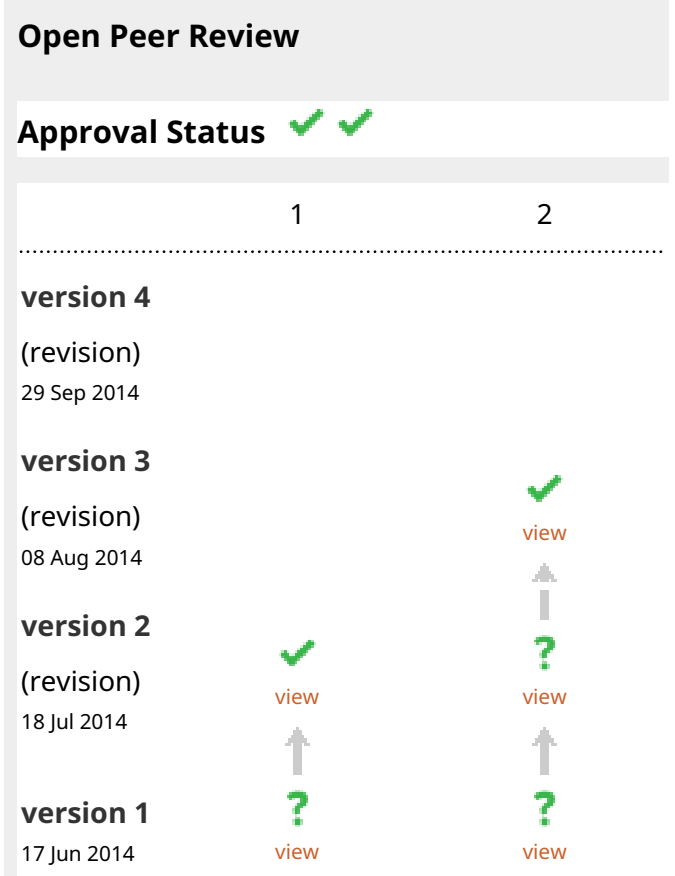

1. Maruyama Koichi, Teikyo University,

Kawasaki, Japan

2. David Healy, University of Michigan, Ann

Arbor, MI, USA

Any reports and responses or comments on the article can be found at the end of the article. 
Corresponding author: Mohamed El-Tahan (mohamedrefaateltahan@yahoo.com)

Competing interests: All authors declare that they have no conflicts of interest and received no financial support for the research, authorship, and/or publication of this article. Dr El Tahan received free airway device samples from Ambu in April 2014 for use in another study and he has no direct financial or other interest in Ambu (in the context of this and other studies).

Grant information: The author(s) declared that no grants were involved in supporting this work.

Copyright: @ $2014 \mathrm{El}$-Tahan $\mathrm{M}$ et al. This is an open access article distributed under the terms of the Creative Commons Attribution License, which permits unrestricted use, distribution, and reproduction in any medium, provided the original work is properly cited. Data associated with the article are available under the terms of the Creative Commons Zero "No rights reserved" data waiver (CC0 1.0 Public domain dedication).

How to cite this article: El-Tahan M, Doyle DJ, Khidr AM and Hassieb AG. Case Report: Double lumen tube insertion in a morbidly obese patient through the non-channelled blade of the King Vision ${ }^{\mathrm{TM}}$ videolaryngoscope [version 3; peer review: 2 approved] F1000Research 2014, 3:129 https://doi.org/10.12688/f1000research.4481.3

First published: 17 Jun 2014, 3:129 https://doi.org/10.12688/f1000research.4481.1 


\section{REVISED Amendments from Version 2}

We made the changes requested by referee (2)

See referee reports

\section{Introduction}

The GlideScope ${ }^{\circledR}$ (Verathon Inc., Bothell, WA, USA) has been used to facilitate the placement of the double lumen endobronchial tubes (DLT) in patients with a difficult airway ${ }^{1,2}$. However, DLT placement in patients with a limited mouth opening is relatively difficult compared to a single-lumen tube (SLT) because of the larger outer diameter, the distal curvature and the increased rigidity ${ }^{3,4}$. The DLT version of the channeled Airtraq ${ }^{\circledR}$ laryngoscopes (Prodol Limited, Viscaya, Spain) is equivalent in performance to direct laryngoscopy with a Macintosh blade ${ }^{4}$.

The King Vision ${ }^{\mathrm{TM}}$ video laryngoscope (King Systems, Indianapolis, IN, USA) is a portable video laryngoscope (VL) similar to the Pentax Airway Scope ${ }^{\circledR}$ (Pentax-AWS, Hoya Corp., Tokyo, Japan), but different in that the LED light and CMOS camera are part of the disposable blades. These blades are available in two styles: a standard non-channeled blade that requires the use of a stylet shaped to $60-70^{\circ}$ to direct the SLT, and a channeled blade that incorporates a guide channel which directs the SLT towards the glottis. Both designs include an anti-fog lens coating. The height and width of the standard non-channeled and channeled blades are $13 \mathrm{~mm}$ and $26 \mathrm{~mm}$ vs. $18 \mathrm{~mm}$ and $29 \mathrm{~mm}$, respectively. Among the Airtraq ${ }^{\circledR}$, the Pentax Airway Scope ${ }^{\circledR}$ and the King Vision ${ }^{\mathrm{TM}}$ VL, the standard non-channeled blade of the King Vision ${ }^{\mathrm{TM}}$ VL has the smallest diameter.

In this report we show how the use of the standard non-channeled blade of the King Vision ${ }^{\mathrm{TM}}$ videolaryngoscope can be useful for DLT placement, as illustrated in the management of a morbidly obese patient with predicted difficult airway and severely restrictive pulmonary dysfunction.

\section{Case report}

A 52 year-old, $151 \mathrm{~cm}, 95 \mathrm{~kg}$ (body mass index $41.7 \mathrm{~kg} / \mathrm{m}^{2}$ ) Asian woman presented with progressive orthopnea, dyspnea, and cough and was admitted to hospital. She had a 15 years history of moderate asthma, hypertension and hypocalcemia and was treated with irbesartan $150 \mathrm{mg} /$ day, furosemide $40 \mathrm{mg} /$ day, calcium carbonate $1.2 \mathrm{~g} /$ day and inhaled salbutamol.

On physical examination, dyspnea on mild exertion was present. The respiratory rate (RR) was $17 / \mathrm{min}$, the resting heart rate (HR) was $80 / \mathrm{min}$, blood pressure (BP) was $150 / 90 \mathrm{mmHg}$ and arterial oxygen saturation $\left(\mathrm{SpO}_{2}\right)$ was $90 \%$ on a room air. Examination of the other systems (including abdomen and central nervous system examinations) revealed no abnormalities. Preoperative airway examination revealed a Mallampati class III airway, with an intercisor distance of $3.5 \mathrm{~cm}$, a thyromental distance of $6.0 \mathrm{~cm}$, normal teeth, and a full range of neck flexion and extension.

Chest radiography showed reticular opacities with honeycombing. Electrocardiography showed left axis deviation and poor $\mathrm{R}$ wave progression. Transthoracic echocardiography showed impaired left ventricular relaxation, mild apical wall hypokinesis and an ejection fraction of 0.55 . The patient's electrolytes and creatinine were normal. Hemoglobin concentration was $12.9 \mathrm{~g} / \mathrm{dl}$ and ionized calcium was $0.7 \mathrm{mmol} / \mathrm{l}$. Pulmonary function testing showed a severe restrictive pattern (forced expiratory volume in first second $\left[\mathrm{FEV}_{1}\right] 44.5 \%$, forced vital capacity [FVC] $40.5 \%$, and $\mathrm{FEV}_{1} / \mathrm{FVC} 109 \%$ of predicted). Arterial blood gases analysis showed hypoxemia on room air (pH 7.39, $\mathrm{PaCO}_{2} 46.6 \mathrm{mmHg}, \mathrm{HCO}_{3} 27.7 \mathrm{mmol} / \mathrm{l}, \mathrm{PaO}_{2} 58 \mathrm{mmHg}$ ).

The patient was scheduled for a video-assisted thoracoscopic lung biopsy. Multidisciplinary discussions involving a cardiothoracic surgeon, a pulmonologist, anesthesiologists and the family of the patients took place, emphasizing the possibility of acute pulmonary compromise during tracheal intubation and surgery. Awake fibreoptic intubation was offered as the best airway management option, but the patient refused. Written informed consent was obtained for tracheal intubation after induction of general anesthesia with the adopted stepwise plan.

A stepwise plan was formulated: the initial plan included induction of general anesthesia through the placement of a left DLT using the King Vision ${ }^{\text {TM }}$ VL. Backup plans were revised involving the insertion of the left DLT over a placed Eschmann tracheal tube introducer (Smiths-Medical International Ltd, Hythe, Kent, UK), and using a King Vision ${ }^{\mathrm{TM}}$ VL, an Arndt's endobronchial blocker placed through a SLT. The use of selective lobar blockade was considered, if needed to correct hypoxemia during lung ventilation.

Oxygen at $3 \mathrm{~L} / \mathrm{min}$ was delivered via a nasal cannula inserted upon entry of the patient in the operating room. Glycopyrrolate $0.2 \mathrm{mg}$ was administered intravenously. Patient monitoring included electrocardiography, pulse oximetry, invasive arterial blood measurement, capnography, train of four stimulation of the ulnar nerve, and entropy-based depth of anesthesia monitoring. A left thoracic paravertebral catheter was inserted. No sedative premedication was given.

After positioning of the patient on the operating table in a headup position, anesthesia was induced using a target-controlled infusion (TCI) of sufentanil with a target effect site concentration (Ce) of $0.1 \mathrm{ng} / \mathrm{mL}$, in conjunction with $8 \%$ sevoflurane in $92 \%$ oxygen delivered by mask ventilation using pressure-support ventilation of $15 \mathrm{~cm} \mathrm{H}_{2} \mathrm{O}$ and with an Aisys anesthesia care station (GE Healthcare, Helsinki, Finland). The patient was easily ventilated using bag mask ventilation (Han et al. grade 1) $)^{5}$. This lasted about $8 \mathrm{~min}$.

Laryngoscopy was performed using a King Vision ${ }^{\mathrm{TM}}$ videolaryngoscope, where a grade II view of the glottis was observed. Succinylcholine $(80 \mathrm{mg}$ ) was then administered intravenously for muscle relaxation.

The stylet of a 35 Fr left DLT (Portex ${ }^{\circledR}$ Blueline Endobronchial tube, Smiths Medical Intl. Ltd., Hythe, Kent) was bent to fit the natural curve of a standard non-channeled blade of a King Vision ${ }^{\mathrm{TM}}$ VL [Figure $1 \mathrm{~A}-\mathrm{C}]$. After mask ventilation, a second laryngoscopy with the introduction of the standard blade of a King Vision ${ }^{\mathrm{TM}}$ VL through the mouth followed with gliding of the left DLT over the posterior surface of the standard non-channeled blade. 


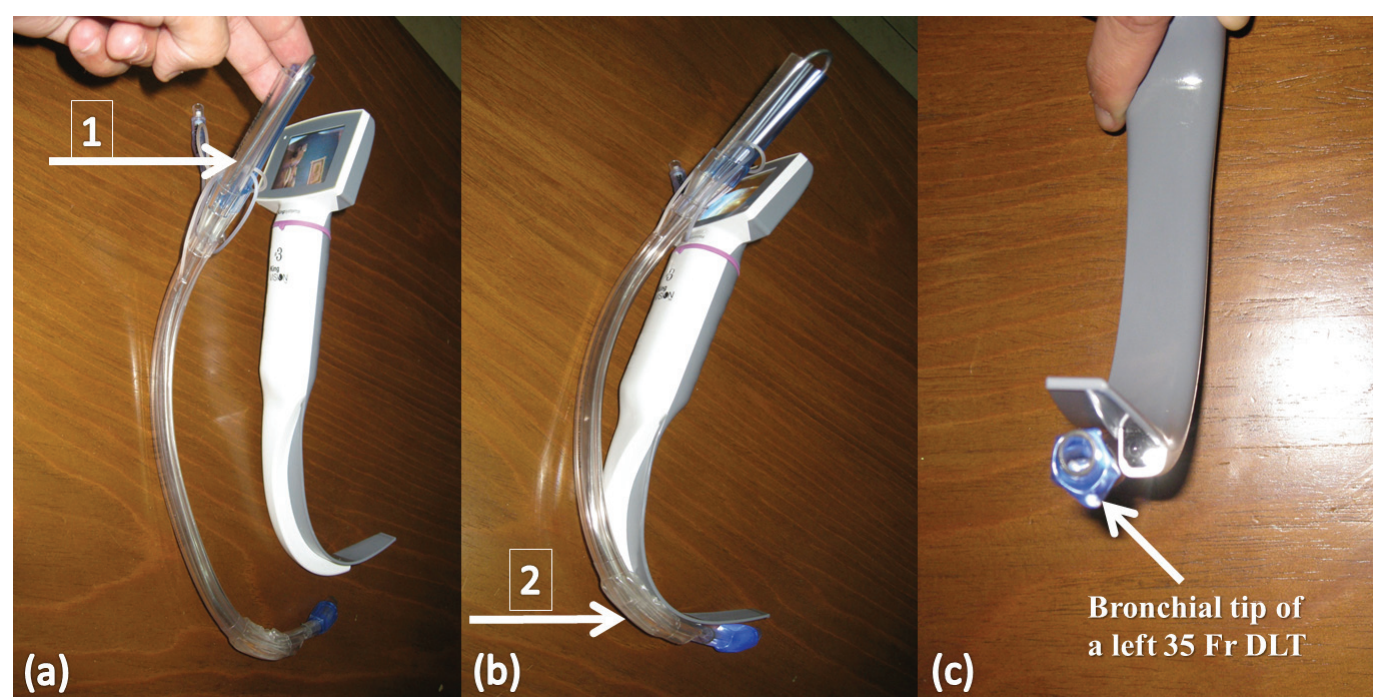

Figure 1. Photograph of a "standard" non-channeled blade of the King Vision ${ }^{\mathrm{TM}}$ videolaryngoscope with a stylet placed in a left $35 \mathrm{Fr}$ double-lumen tube (DLT) to match the contour of the blade. (a) Arrow (1) shows how the proximal DLT curve remains directed to the right side. (b) Arrow (2) shows how the distal DLT curve follows the curve of the standard non-channeled blade (approximately $60-70^{\circ}$ ). (c) Shows the bronchial tip of the DLT adapted to the tip of the standard non-channeled blade.

After satisfactory visualization, the left DLT was directed through the glottic opening into the trachea [Figure 2A-C]. The operator's index finger prevented the perforation of the tracheal cuff of the DLT by the sharp upper teeth during passage through the mouth opening. The stylet was then removed and the DLT rotated counterclockwise $180^{\circ}$ and advanced to the $27 \mathrm{~cm}$ mark at the incisors, while the glottis was visualized via the King Vision ${ }^{\mathrm{TM}}$ VL. The DLT position was verified fibreoptically.

The time from the cessation of mask ventilation until resumption of mechanical ventilation following intubation was about $90 \mathrm{~s}$. The lowest $\mathrm{SpO}_{2}$ during intubation was $95 \%$.
Anesthesia was maintained with sevoflurane (0.8-0.9 minimum alveolar concentration), TCI sufentanil with a Ce of $0.1 \mathrm{ng} / \mathrm{mL}$ and cisatracurium $5 \mathrm{mg}$. Transient severe hypotension (BP was $57-78 / 42-52 \mathrm{mmHg}$ that lasted for $25 \mathrm{~min}$ ) was treated with reducing the sufentanil Ce to $0.05 \mathrm{ng} / \mathrm{ml}$, and administering boluses of $6 \%$ hydroxyethyl starch 130/0.4 (Voluven ${ }^{\circledR} 6 \%$, Hospira, Fresenius Kabi, Halden, Norway), as well as phenylephrine (300 $\mu \mathrm{g})$ and ephedrine (10 mg).

The patient's right lung was ventilated in pressure-controlled ventilation mode, with $\mathrm{FiO}_{2}$ set at 0.7 , a delivered tidal volume (TV) of $360 \mathrm{~mL}$, an inspiratory-to-expiratory [I: E] ratio of 1:2, PEEP of

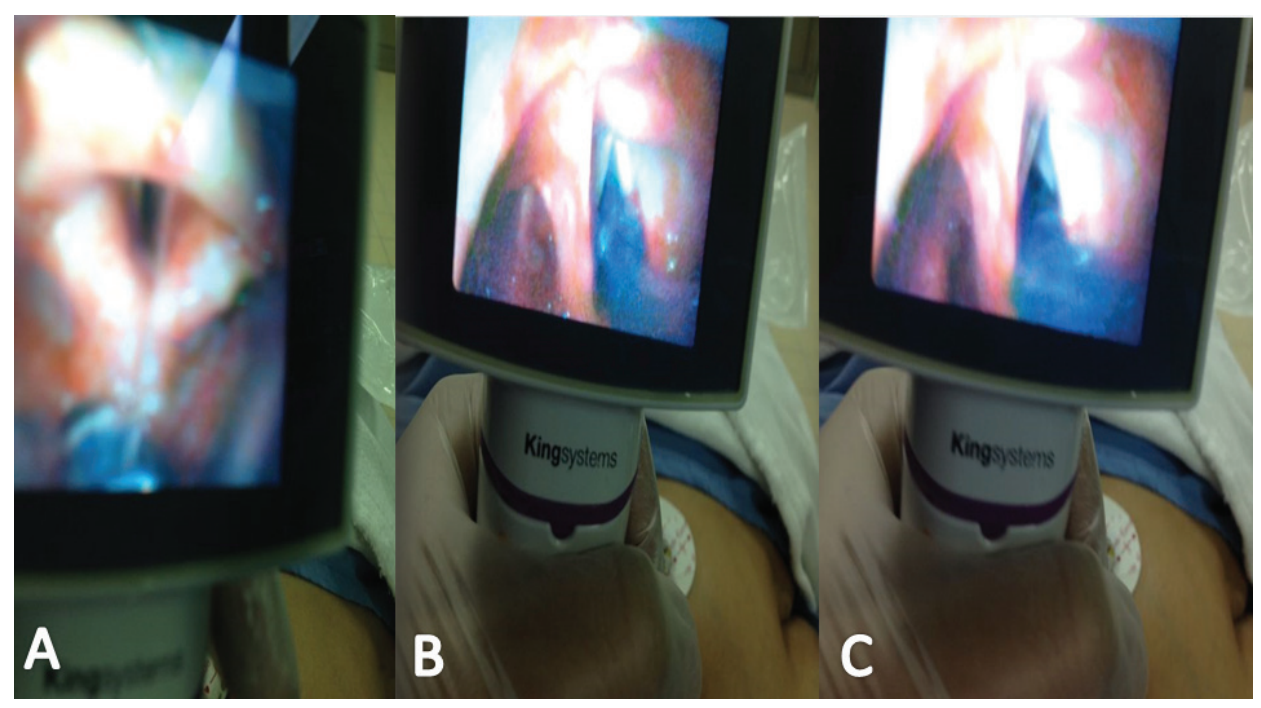

Figure 2. Photograph showing a bronchial tip of a left $35 \mathrm{Fr}$ double-lumen tube (DLT) passing towards (A) and through (B) the vocal cords, and (C) following removal of the stylet and $180^{\circ}$ counterclockwise rotation of the DLT through the display unit of a King Vision ${ }^{\mathrm{TM}}$ videolaryngoscope. 
$5 \mathrm{~cm} \mathrm{H} \mathrm{H}_{2} \mathrm{O}$, and $\mathrm{RR}$ of $14-16 / \mathrm{min}$. The peak airway pressure (Ppk) was limited to $35 \mathrm{~cm} \mathrm{H}_{2} \mathrm{O}$ and a fresh gas flow (FGF) of $1.6 \mathrm{~L} / \mathrm{min}$ was used. Neither continuous positive airway pressure (CPAP) nor high frequency positive pressure ventilation (HFPPV) was needed for the non-dependent lung ${ }^{6} ; \mathrm{SpO}_{2}$ was maintained over $92 \%$ during 25 minutes of one lung ventilation (OLV). The operation proceeded uneventfully, with excellent lung isolation.

After the surgery, the residual effects of neuromuscular blockade were reversed with neostigmine $2.5 \mathrm{mg}$ and glycopyrrolate $0.6 \mathrm{mg}$. The patient was extubated and post-operative analgesia was accomplished with a continuous infusion of bupivacaine $0.125 \%$ through the paravertebral catheter. A post-operative follow-up (for the next six days after surgery) showed no evidence of hoarseness.

\section{Discussion}

Two main techniques can be used to achieve lung isolation in patients with a predicted difficult airway: [1] using a DLT or [2] using a bronchial blocker inserted through a SLT. There is no overall advantage of either over the other in the morbidly obese patient ${ }^{7}$.

Our patient had predictable hypoxemia during OLV because of a severe restrictive pulmonary dysfunction and a low $\mathrm{PaO}_{2}$; despite this, significant hypoxemia was not noted during the relatively short period of $\mathrm{OLV}^{8}$. A DLT was chosen over a bronchial blocker so that the non-ventilated non-dependent lung could be oxygenated using HFPPV, although a bronchial blocker could have been used to provide CPAP to the non-ventilated non-dependent lung ${ }^{6}$. Additionally, a DLT allows effective bilateral suctioning. The difficulty in surgical access precluded the use of selective lower lobar collapse, which could have been helpful to correct the predicted intraoperative hypoxemia during OLV. In a manner similar to others $^{9,10}$, pressure support pre-oxygenation was used to improve baseline arterial oxygen saturation before and during induction of general anesthesia; this succeeded in maintaining $\mathrm{SpO}_{2} \geq 95 \%$ during intubation.

The true difficulty of intubation using standard direct laryngoscopy remains unknown. We chose not to attempt direct laryngoscopy prior to the use of the King Vision ${ }^{\mathrm{TM}}$ VL. First, the patient had three predictors of an anticipated difficult airway, including a BMI of $41.7 \mathrm{~kg} / \mathrm{m}^{2}$, a short thyromental distance and a limited mouth opening. Second, we were concerned about the possibility of hypoxemia in case of extended time of laryngoscopy and intubation due to a prior assessment of the airway using direct laryngoscopy. We thus felt that prior assessment of the airway using direct laryngoscopy would have not changed the adopted plan and would have conferred little benefit. Third, the recent ASA Guidelines for Management of the Difficult Airway ${ }^{11}$ do not suggest a prior assessment using direct laryngoscopy. The guidelines also suggest the use of VL as a choice for tracheal intubation in the non-emergent pathway where ventilation is adequate. Finally, an improved view of the glottis does not always translate into easier tracheal intubation. The ease of intubation depends on many factors: (i) the type and size of the videolaryngoscope; (ii) the experience of the laryngoscopist; (iii) the use of external laryngeal manipulation; (iv) the optimization of head positioning; and (v) the use of adjuncts such as a stylet ${ }^{12}$. In the present case, endobronchial intubation was successfully performed during the first intubation attempt by an anesthesiologist who has an experience with more than 200 tracheal intubations using King Vision ${ }^{\mathrm{TM}} \mathrm{VL}$.

Videolaryngoscopy can sometimes facilitate DLT insertion compared with direct laryngoscopy ${ }^{13,14}$. Other investigators have reported $17 \%$ to $27 \%$ reductions in time to intubation with a DLT compared with direct laryngoscopy ${ }^{15,16}$. Wojtczak recommended the routine use of videolaryngoscopy during all elective intubations to avoid any trauma from failed direct laryngoscopy, as well as to reduce the patient's stress response to intubation (and our own stress) ${ }^{17}$. Channeled VLs have a number of advantages over those with angulated blades, such as the GlideScope ${ }^{\circledast}$, and has been found to shorten the time taken to position the endotracheal tube in a small manikin study $^{18}$. Channeled VLs have a passage to guide the SLT; thus, once an adequate view of the glottis has been obtained, the VL is kept steady and the SLT advanced into the glottis with the right hand. By contrast, the angulated blade design uses a different technique for placing the SLT: once an adequate view of the glottis is obtained, the operator holds the laryngoscope with the left hand and manipulates the SLT into the glottis with the right hand using the view on the screen is used as a guide ${ }^{18}$.

Channeled videolaryngoscopes are more suitable in patients with a limited mouth opening compared to traditional videolaryngoscopes like the GlideScope ${ }^{\circledR 19-21}$.

The King Vision ${ }^{\mathrm{TM}}$ VL accommodates a minimum mouth opening of $13 \mathrm{~mm}$ for the standard non-channeled blade and $18 \mathrm{~mm}$ for the channeled blade. Studies in manikins point to improved laryngeal visualization with the use of the Airtraq ${ }^{\circledR}$ VL over the GlideScope ${ }^{\circledR 22-24}$.

However, the large outer diameter and more rigid design of DLTs make them relatively harder to insert it through classic channeled blades. This requires either the use of a specific videolaryngoscope design like the DLT version of the Airtraq ${ }^{\circledR 4}$, or the use of a tube exchanger over which a large DLT can be placed ${ }^{25}$. The DLT Airtraq ${ }^{\circledR}$ laryngoscope is available for the 35 Fr to 41 Fr DLTs. However, it has not gained widespread popularity because it requires a minimum mouth opening of $19 \mathrm{~mm}$, provides only subtle enhancement of visualization, has a higher incidence of hoarseness over the Macintosh laryngoscopes ${ }^{4}$, and has a narrower field of view than King Vision ${ }^{\mathrm{TM}}$ VL $\left(80^{\circ} \text { vs. } 160^{\circ}\right)^{26}$. Regardless, a superior field of view does not necessarily result in an improved view of the laryngeal inlet, or leads to easier insertion of the tracheal tube ${ }^{4}$.

Suzuki et al. described the removal of the tube channel back plate of the Airway Scope ${ }^{\circledR}$ for intubation with a 39 Fr DLT in a patient with unpredicted difficult intubation and inadequate mouth opening $^{27}$. Compared with the Airtraq ${ }^{\circledR}$ and the Pentax Airway Scope ${ }^{\circledR}$, the standard non-channeled blade King Vision ${ }^{\mathrm{TM}}$ VL has the thinnest and shortest stature (26 mm vs. $28 \mathrm{~mm}$ and $49 \mathrm{~mm}$ and $13 \mathrm{~mm}$ vs. $18 \mathrm{~mm}$ and $131 \mathrm{~mm}$, respectively) and the widest field of view $\left(160^{\circ}\right.$ vs. $80^{\circ}$ and $90^{\circ}$, respectively), the dimensions of which may make it superior for those with limited mouth opening ${ }^{26-28}$. 
Although the use of video laryngoscopy for placement of DLTs has been well described, the present report describes a novel approach to DLT intubation and offers another tool for patients who require lung isolation. The standard non-channeled blade of the King Vision ${ }^{\mathrm{TM}}$ VL could provide a new mean for insertion of DLTs in patients with a minimum mouth opening of $13 \mathrm{~mm}$. This approach offers a $160^{\circ}$ field of view, potentially facilitating the manipulation and rotation of the DLT upon visualization.

Akihisa et al. ${ }^{29}$ have reported longer intubation times with the use of the non-channeled King Vision ${ }^{\mathrm{TM}}$ laryngoscope compared to the conventional Macintosh laryngoscope or the channeled King Vision $^{\mathrm{TM}}$ video laryngoscopes. However, the results of that particular study cannot readily be applied to the present case report because the operators were non-experienced nurses who had never previously performed a tracheal intubation (rather than anesthesiologists with over 10 years of experience, as in the present report). In addition, the Akihisa study was done on manikins with simulated normal airways rather than patients with a difficult airway, and it tested the efficacy of the tested devices using a single lumen tube rather than a larger double lumen tube.

Here we described the necessary maneuvers to insert a DLT using a standard non-channeled blade of King Vision ${ }^{\mathrm{TM}}$ VL. We recommend four steps: first, bend the DLT stylet so that the distal $21 \mathrm{~cm}$ of the DLT curve follows the curve of the standard non-channeled blade and the proximal curve of the DLT remains directed to the right side. Next, insert the DLT, exercising caution to avoid damage to the tracheal cuff by the upper teeth during its passage through the mouth opening. Then, after the bronchial cuff passes through the vocal cords, withdraw the stylet of the DLT. Finally, rotate the DLT $180^{\circ}$ counterclockwise while advancing the DLT to the desired depth. In conclusion, the use of King Vision ${ }^{\mathrm{TM}}$ videolaryngoscope could offer an effective method of DLT placement for OLV.

\section{Consent}

The patient provided informed written consent for the publication of this report.

\section{Author contributions}

Drs Mohamed R El-Tahan and D. John Doyle contributed equally to this work as they were involved in designing the case presentation, and revised the manuscript critically for important intellectual content. Mohamed R El-Tahan reviewed the literature and wrote the manuscript. Mohamed R El-Tahan, Alaa M Khidr and Ahmed $\mathrm{G}$ Hassieb cared for the patient and revised the manuscript. Alaa M Khidr provided the patient's pictures and is the author responsible for archiving the study files. Mohamed R El-Tahan submitted the final version of the manuscript. All authors approved the final version of the manuscript.

\section{Competing interests}

All authors declare that they have no conflicts of interest and received no financial support for the research, authorship, and/or publication of this article. Dr El Tahan received free airway device samples from Ambu in April 2014 for use in another study and he has no direct financial or other interest in Ambu (in the context of this and other studies).

\section{Grant information}

The author(s) declared that no grants were involved in supporting this work.
1. Hernandez AA, Wong DH: Using a Glidescope for intubation with a double lumen endotracheal tube. Can J Anaesth. 2005; 52(6): 658-659. PubMed Abstract | Publisher Full Text

2. Chen A, Lai HY, Lin PC, et al:: GlideScope-assisted double-lumen endobronchial tube placement in a patient with unanticipated difficult airway. $J$ Cardiothorac Vasc Anesth. 2008; 22(1): 170-172. PubMed Abstract | Publisher Full Text

3. Russell T, Slinger P, Roscoe A, et al:: A randomised controlled trial comparing the GlideScope $\left({ }^{\circledR}\right)$ and the Macintosh laryngoscope for double-lumen endobronchial intubation. Anaesthesia. 2013; 68(12): 1253-1258. PubMed Abstract | Publisher Full Text

4. Wasem S, Lazarus M, Hain J, et al.: Comparison of the Airtraq and the Macintosh laryngoscope for double-lumen tube intubation: a randomised clinical trial. Eur J Anaesthesiol. 2013; 30(4): 180-186. PubMed Abstract | Publisher Full Text

5. Han R, Tremper KK, Kheterpal S, et al:: Grading scale for mask ventilation. Anesthesiology. 2004; 101(1): 267. PubMed Abstract | Publisher Full Text

6. El-Tahan MR, El Ghoneimy YF, Regal MA, et al:: Comparative study of the nondependent continuous positive pressure ventilation and high-frequency positive-pressure ventilation during one-lung ventilation for video-assisted thoracoscopic surgery. Interact Cardiovasc Thorac Surg. 2011; 12(6): 899-902. PubMed Abstract | Publisher Full Text

7. Campos $\mathrm{JH}$, Hallam EA, Ueda $\mathrm{K}$ : Lung isolation in the morbidly obese patient: a comparison of a left-sided double-lumen tracheal tube with the Arndt ${ }^{\oplus}$ wire-guided blocker. Br J Anaesth. 2012; 109(4): 630-635. PubMed Abstract | Publisher Full Text

8. Liu TJ, Shih MS, Lee WL, et al:: Hypoxemia during one-lung ventilation for robot-assisted coronary artery bypass graft surgery. Ann Thorac Surg. 2013; 96(1): 127-132.

PubMed Abstract | Publisher Full Text

9. Langeron $\mathrm{O}$, Masso $\mathrm{E}$, Huraux $\mathrm{C}$, et al.: Prediction of difficult mask ventilation. Anesthesiology. 2000; 92(5): 1229-1236.

PubMed Abstract

10. Harbut $P$, Gozdzik W, Stjernfält $E$, et al.: Continuous positive airway pressure/ pressure support pre-oxygenation of morbidly obese patients. Acta Anaesthesiol Scand. 2014; 58(6): 675-680. PubMed Abstract | Publisher Full Text

11. Apfelbaum JL, Hagberg CA, Caplan RA, et al:: Practice guidelines for management of the difficult airway: an updated report by the American Society of Anesthesiologists Task Force on Management of the Difficult Airway. Anesthesiology. 2013; 118(2): 251-270. PubMed Abstract | Publisher Full Text

12. Angadi SP, Frerk C: Videolaryngoscopy and Cormack and Lehane grading. Anaesthesia. 2011; 66(7): 628-629. PubMed Abstract | Publisher Full Text

13. Purugganan RV, Jackson TA, Heir JS, et al:: Video laryngoscopy versus direct laryngoscopy for double lumen endotracheal tube intubation: a retrospective analysis. J Cardiothorac Vasc Anesth. 2012; 26(5): 845-848. PubMed Abstract | Publisher Full Text 
14. Yang M, Kim JA, Ahn HJ, et al.: Double-lumen tube tracheal intubation using a rigid video-stylet: a randomized controlled comparison with the Macintosh laryngoscope. Br J Anaesth. 2013; 111(6): 990-995.

PubMed Abstract | Publisher Full Text

15. Bensghir $\mathrm{M}$, Alaoui $\mathrm{H}$, Azendour $\mathrm{H}$, et al.: [Faster double-lumen tube intubation with the videolaryngoscope than with a standard laryngoscope]. Can $J$ Anaesth. 2010; 57(11): 980-984.

PubMed Abstract | Publisher Full Text

16. Hsu HT, Chou SH, Wu PJ, et al:: Comparison of the GlideScope ${ }^{\circledast}$ videolaryngoscope and the Macintosh laryngoscope for double-lumen tube intubation. Anaesthesia. 2012; 67(4): 41-415.

PubMed Abstract | Publisher Full Text

17. Wojtczak JA: Should videolaryngoscopy be used routinely during all elective intubations? Minerva Anestesiol. 2012; 78(9): 1076-1077. PubMed Abstract

18. Savoldelli GL, Schiffer E, Abegg C, et al:: Learning curves of the Glidescope, the McGrath and the Airtraq laryngoscopes: a manikin study. Eur J Anaesthesiol. 2009; 26(7): 554-558.

PubMed Abstract | Publisher Full Text

19. Panacek EA, Laurin EG, Bair AE: Fracture of a GlideScope ${ }^{\circledR}$ Cobalt GVL ${ }^{\circledR}$ Stat disposable blade during an emergency intubation. J Emerg Med. 2012; 42(6): e125-812.

PubMed Abstract | Publisher Full Text

20. Xue FS, Yang QY, He N, et al.: The modified ventilating tube changer to facilitate tracheal intubation using the GlideScope in patients with a limited mouth opening. Br J Anaesth. 2008; 101(1): 126-127.

PubMed Abstract | Publisher Full Text

21. Xue FS, Zhang GH, Liu J, et al:: The clinical assessment of Glidescope in orotracheal intubation under general anesthesia. Minerva Anestesiol. 2007; 73(9): 451-457.

PubMed Abstract
22. Putz L, Dangelser G, Constant B, et al.: [Prospective trial comparing Airtraq and Glidescope techniques for intubation of obese patients]. Ann Fr Anesth Reanim. 2012; 31(5): 421-426.

PubMed Abstract | Publisher Full Text

23. Darshane S, Ali M, Dhandapani S, et al:: Validation of a model of graded difficulty in Laerdal SimMan: functional comparisons between Macintosh, Truview EVO2, Glidescope Video Laryngoscope and Airtraq. Eur J Anaesthesiol. 2011; 28(3): 175-180.

PublMed Abstract | Publisher Full Text

24. McElwain J, Malik MA, Harte BH, et al.: Comparison of the C-MAC videolaryngoscope with the Macintosh, Glidescope, and Airtraq laryngoscopes in easy and difficult laryngoscopy scenarios in manikins. Anaesthesia. 2010; 65(5): 483-489. PubMed Abstract | Publisher Full Text

25. Poon $\mathrm{KH}$, Liu EH: The Airway Scope for difficult double-lumen tube intubation J Clin Anesth. 2008; 20(4): 319.

PubMed Abstract | Publisher Full Text

26. White MC, Marsh CJ, Beringer RM, et al: A randomised, controlled trial comparing the Airtraq ${ }^{\mathrm{TM}}$ optical laryngoscope with conventional laryngoscopy in infants and children. Anaesthesia. 2012; 67(3): 226-231. PubMed Abstract | Publisher Full Text

27. Suzuki A, Kunisawa T, Iwasaki H: Double lumen tube placement with the PentaxAirway Scope. Can J Anaesth. 2007; 54(10): 853-854. PubMed Abstract | Publisher Full Text

28. Saracoglu KT, Eti Z, Gogus FY: Airtraq optical laryngoscope: advantages and disadvantages. Middle East J Anesthesiol. 2013; 22(2): 135-141. PubMed Abstract

29. Akihisa $Y$, Maruyama K, Koyama Y: Comparison of intubation performance between the King Vision and Macintosh laryngoscopes in novice personnel: a randomized, crossover manikin study. J Anesth. 2014; 28(1): 51-57.

PubMed Abstract | Publisher Full Text 


\section{Open Peer Review}

\section{Current Peer Review Status:}

\section{Version 3}

Reviewer Report 25 September 2014

https://doi.org/10.5256/f1000research.5242.r5755

(C) 2014 Healy D. This is an open access peer review report distributed under the terms of the Creative Commons Attribution License, which permits unrestricted use, distribution, and reproduction in any medium, provided the original work is properly cited.

\section{David Healy}

Department of Anesthesiology, University of Michigan, Ann Arbor, MI, USA

Thank you for giving me the chance to review this well-written and interesting case report with comment.

The authors have made significant efforts to clarify the case, and modify their introduction and discussion points.

I approve this manuscript, but I have 2 remaining reservations which I would like the authors to consider:

The discussion retains two statements that should be qualified with the word "may" as the evidence for the statements are limited, namely:

1. "Channeled VLs have a number of advantages over those with angulated blades, such as the GlideScope ${ }^{\circledR} "$ - They may have advantages, but the evidence remains weak, and is likely dependent (as previously stated by the authors, to device familiarity and availability).

2. "Channeled videolaryngoscopes are more suitable in patients with a limited mouth opening compared to traditional videolaryngoscopes like the GlideScope ${ }^{\circledR}$ " - Again, they may have advantages, but the evidence remains weak. Because a device can "fit through the incisor gap" doesn't necessarily mean it performs better when placing a tube into the trachea. Again, I do not wish to hold up the indexing of this interesting case study based on pedantics but I feel we must be careful when providing broad comments that may be falsely reassuring, and lead to incorrect assumptions of the performance of one device of another.

Competing Interests: No competing interests were disclosed.

I confirm that I have read this submission and believe that I have an appropriate level of expertise to confirm that it is of an acceptable scientific standard. 
Reader Comment 25 Sep 2014

Mohamed El Tahan, Dammam University, Saudi Arabia

We made the changes requested by David Healy in the V4. Thank you so much for your kind effort to improve our report.

Competing Interests: None declared

\section{Version 2}

Reviewer Report 22 July 2014

https://doi.org/10.5256/f1000research.5142.r5496

(C) 2014 Healy D. This is an open access peer review report distributed under the terms of the Creative Commons Attribution License, which permits unrestricted use, distribution, and reproduction in any medium, provided the original work is properly cited.

\section{David Healy}

Department of Anesthesiology, University of Michigan, Ann Arbor, MI, USA

Thank you for the opportunity to re-review this manuscript following the authors' changes, additions, and clarifications. As before, this is a well written discussion of a challenging airway management scenario. The manuscript is greatly improved with the authors careful edits. I do however, have several reservations with the manuscript primarily related to unsupported statements and low quality references.

\section{Technical issues:}

I appreciate the authors clarification regarding the previous technical concerns. Thank you for drawing my attention to the ability to bag mask ventilate expressed as "mask ventilation using pressure-support ventilation of $15 \mathrm{~cm} \mathrm{H}_{2} \mathrm{O}$ " - to clarify, does the manuscript mean manual airway support, the application of a face mask, and the ventilator turned on?

The degree of difficulty in ability to bag mask ventilate changes the entire clinical context of this patient's airway management. I suggest this is expressed according to the Han grade for clarification (Hans et al., 2004).

I suggest the inclusion of a statement regarding the fact that the true difficulty of intubation (according to the standard of direct laryngoscopy) remains unknown. The authors have explained the reasons for progressing directly to videolaryngoscopy, but being at high risk of difficulty is 
distinct from true difficulty. In response to the authors reply previous reply, the ASA guidelines do not actually recommend the use of videolaryngoscopy in a predicted difficult intubation - they suggest the consideration of it. This is an important, but admittedly subtle, distinction. I agree the guidelines do not specifically recommend or suggest (see previous) a check DL view before progression to videolaryngoscopy, but it does not make it a bad idea (especially in a stable patient receiving adequate bag mask ventilation).

\section{Content issues:}

Please consider removal of the statement "Channelled video laryngoscopes are more suitable in patients with a limited mouth opening compare to traditional videolarygoscopes like the GlideScope". This may or may not be true, but it isn't supported by the current reference, which describes a manikin study. e.g. to be correct would need to rephrase "Channelled video laryngoscopes have been shown to be advantageous when performing intubations in manikins with limited mouth opening..." which is more accurate, but reduces the relevance of the statement.

Please consider removal of the statement "the King Vision view was a grade II, therefore the $\mathrm{CL}$ view would be higher". This is speculative. As stated previously the DL C\&L view remains unknown as it was never performed, and can not be estimated from the visualization findings of a different device.

Please consider removal or rephrase the statement "Channeled VLs have a number of advantages over those with angulated blades, such as the GlideScope, and may shorten the time taken to position the endotracheal tube" - this is referenced with a manikin study, to be correct this should be rephrased "and was found to shorten the time taken to position the endotracheal tube in a small manikin study"

Please consider clarification of the referenced statement, "Previous studies have demonstrated the Airtraq VL to provide improved laryngeal visualization of than the GlideScope." The manuscript refers to 2 manikin studies, and one prospective study where no statistically significant difference in grade I/II vs III/IV between the GlideScope and Airtraq groups were found. For inclusion this should be phrased "Studies in manikins have suggested an improved laryngeal visualization with use of the Airtraq over the GlideScope". Again this is more accurate, but reduces the relevance of the statement.

Please consider modifying the statement "that makes it superior for those with limited mouth opening" to "the dimensions of which may make it superior..." as the referenced articles do not address this statement.

Competing Interests: No competing interests were disclosed. 


\section{I confirm that I have read this submission and believe that I have an appropriate level of expertise to confirm that it is of an acceptable scientific standard, however I have significant reservations, as outlined above.}

\section{Author Response 26 Jul 2014}

Mohamed El Tahan, Dammam University, Saudi Arabia

We read with interest the important comments of Dr. David Healy, Department of Anesthesiology, University of Michigan, Ann Arbor, MI, USA. Here are our responses to his comments:

\section{Technical Issues:}

1. Dr. Healy: "Thank you for the opportunity to re-review this manuscript following the authors' changes, additions, and clarifications. As before, this is a well written discussion of a challenging airway management scenario. The manuscript is greatly improved with the authors careful edits. I do however, have several reservations with the manuscript primarily related to unsupported statements and low quality references."

Authors': Thank you so much. We addressed your reservations one by one as follows:

2. Dr. Healy: "I appreciate the authors clarification regarding the previous technical concerns. Thank you for drawing my attention to the ability to bag mask ventilate expressed as "mask ventilation using pressure-support ventilation of $15 \mathrm{~cm} \mathrm{H}_{2} \mathrm{O}$ " - to clarify, does the manuscript mean manual airway support, the application of a face mask, and the ventilator turned on?"

Authors: That is correct. We meant that a face mask was applied and a pressuresupport ventilation mode of an Aisys anesthesia care station (GE Healthcare, Helsinki, Finland).

3. Dr. Healy: "The degree of difficulty in ability to bag mask ventilate changes the entire clinical context of this patient's airway management. I suggest this is expressed according to the Han grade for clarification (Hans et al., 2004)."

Authors: The present case had only one predictor of difficult mask ventilation, that was the body mass index of $41.7 \mathrm{~kg} / \mathrm{m}^{2}{ }^{1}$ The patient was easily ventilated by a bag mask ventilation (Hans grade 1). Similar to others ${ }^{2}$, a pressure support preoxygenation was used in the present case to improve her baseline low arterial oxygen saturation before and during induction of general anesthesia, that succeeded to maintain $\mathrm{SpO}_{2} \geq 95 \%$ during intubation.

4. Dr. Healy: "I suggest the inclusion of a statement regarding the fact that the true difficulty of intubation (according to the standard of direct laryngoscopy) remains unknown." 
Authors: Well, we added a statement as follows "The true difficulty of intubtion according to the standard of direct laryngoscopy remains unknown". However, we have few comments about that raised point. First; Cavus et al. ${ }^{3}$, have reported improved Cormack and Lehane laryngoscopy grades from 3 or 4 to 1 or $2 a$ with the use of C-Mac VL D blade. Thus, the use of VLs is quite unlike intubation via direct vision with a standard Macintosh blade where the challenging part of the process is usually obtaining the appropriate Cormack and Lehane view, rather than passing the endotracheal tube into the trachea per se. ${ }^{4}$ Second, the improved view could not always be translated into easier tracheal intubation. The ease of intubation depends on many factors like as (i) name and size of the videolaryngoscope; (ii) grade/experience of the laryngoscopist; (iii) number of attempts; (iv) optimising position/use of adjuncts; and (v) easy/difficult/failed intubation. ${ }^{5}$ In the present case, endobronchial intubation was successfully performed during the first attempt of intubation by an anesthesiologist who has an experience with more than 200 tracheal intubations using King Vision VL. Third, the limited mouth opening in the present case would preclude the easy passage of a $35 \mathrm{Fr}$ left DLT with its larger outer diameter than a $8.0 \mathrm{~mm}$ SLT.

5. Dr. Healy: "The authors have explained the reasons for progressing directly to videolaryngoscopy, but being at high risk of difficulty is distinct from true difficulty.

Authors: That is correct. Please, refer to the $2^{\text {nd }}$ point in our response (no. 4). Additionally, in the view of the low baseline values of $\mathrm{SpO}_{2}$ in the present case, we planned to proceed directly with King Vision to shorten the duration of laryngoscopy and endobronchial intubation and hence the risk of worsening of her noted hypoxemia. Similarly, other investigators have reported $17 \%$ to $27 \%$ shorter time to intubation with a DLT compared with the direct laryngoscopy in elective thoracic surgery. ${ }^{6-7}$ Wojtczak recommended a routine use of videolaryngoscopy during all elective intubations to avoid trauma of failed direct laryngoscopy, reduce the patient's stress response to intubation and our own stress, and to avoid losing valuable seconds to retrieve a unit. $^{8}$

6. Dr. Healy: "In response to the authors reply previous reply, the ASA guidelines do not actually recommend the use of videolaryngoscopy in a predicted difficult intubation they suggest the consideration of it. This is an important, but admittedly subtle, distinction."

Authors: Fortunately, the An Updated Report by the American Society of Anesthesiologists Task Force on Management of the Difficult Airway included "the use of video-assisted laryngoscopy as an initial approach to intubation", in patients with predicted difficult airway after induction of anesthesia in the Non-Emergency Pathway (Appendix 1: Summary of Recommendations, Page 259, Column 2, Lines 11 12)

7. Dr. Healy: "I agree the guidelines do not specifically recommend or suggest (see previous) a check DL view before progression to videolaryngoscopy, but it does not make it a bad idea (especially in a stable patient receiving adequate bag mask 
ventilation)."

Authors: We agree that it could be not a good idea. However, it does not meet the standards of care for such cases, especially after the revolution of VLs.

\section{Content Issues:}

1. Dr. Healy: "Please consider removal of the statement "Channelled video laryngoscopes are more suitable in patients with a limited mouth opening compare to traditional videolarygoscopes like the GlideScope". This may or may not be true, but it isn't supported by the current reference, which describes a manikin study. e.g. to be correct would need to rephrase "Channelled video laryngoscopes have been shown to be advantageous when performing intubations in manikins with limited mouth opening..." which is more accurate, but reduces the relevance of the statement."

Authors: We amended it. We changed the references. Other investigators have reported difficulty in introducing of the SLT in patients with a limited mouth opening, despite the obtained clear view of the glottis with the non-channelled Glidescope due to the wide and square design of its blade. ${ }^{9}$ The limitation in mouth opening could has the potential to break the disposable plastic GVL ${ }^{\circledR}$ Stat blade of a Glidescope during repositioning of the handle back to midline. ${ }^{10}$ However, a limited mouth opening in a morbidly obese patient with a BMI $>40 \mathrm{~kg} / \mathrm{m}^{2}$ might be responsible for broken of the disposable plastic GVL ${ }^{\circledR}$ Stat blade of a non-channelled Glidescope during repositioning of the handle back to midline. ${ }^{11}$

2. Dr. Healy: "Please consider removal of the statement "the King Vision view was a grade II, therefore the CL view would be higher". This is speculative. As stated previously the DL C\&L view remains unknown as it was never performed, and can not be estimated from the visualization findings of a different device."

\section{Authors: We removed it.}

3. Dr. Healy: "Please consider removal or rephrase the statement "Channeled VLs have a number of advantages over those with angulated blades, such as the GlideScope, and may shorten the time taken to position the endotracheal tube" - this is referenced with a manikin study, to be correct this should be rephrased "and was found to shorten the time taken to position the endotracheal tube in a small manikin study"

Authors: We amended it.

4. Dr. Healy: "Please consider clarification of the referenced statement, "Previous studies have demonstrated the Airtraq VL to provide improved laryngeal visualization of than the GlideScope." The manuscript refers to 2 manikin studies, and one prospective study where no statistically significant difference in grade I/II vs III/IV between the GlideScope and Airtraq groups were found. For inclusion this should be phrased "Studies in manikins have suggested an improved laryngeal visualization with use of the Airtraq over the GlideScope". Again this is more accurate, but reduces 
the relevance of the statement."

Authors: We amended it.

5. Dr. Healy: "Please consider modifying the statement "that makes it superior for those with limited mouth opening" to "the dimensions of which may make it superior..." as the referenced articles do not address this statement."

Authors: We amended it.

\section{References}

1. Langeron O, Masso E, Huraux C, Guggiari M, et al.: Prediction of difficult mask ventilation. Anesthesiology. 2000; 92 (5): 1229-1236 PubMed Abstract | Reference Source

2. Harbut P, Gozdzik W, Stjernfalt E, Marsk R, et al.: Continuous positive airway pressure/pressure support pre-oxygenation of morbidly obese patients.Acta Anaesthesoil Scand. 2014; 58 (6): 675-680 PubMed Abstract | Publisher Full Text | Reference Source 3. Cavus E, Neumann T, Doerges V, Moeller T, et al.: First clinical evaluation of the C-MAC DBlade videolaryngoscope during routine and difficult intubation.Anesth Analg. 2011; 112 (2): 382-385 PubMed Abstract | Publisher Full Text | Reference Source

4. Gray H: Use of Cormack and Lehane grading with videolaryngoscopy. Anaesth Intensive Care. 2013; 41 (1): 123-124 PubMed Abstract

5. Angadi SP, Frerk C: Videolaryngoscopy and Cormack and Lehane grading.Anaesthesia. 2011; 66 (7): 628-629 PubMed Abstract | Publisher Full Text | Reference Source 6. Bensghir $\mathrm{M}$, Alaoui $\mathrm{H}$, Azendour $\mathrm{H}$, Drissi $\mathrm{M}$, et al.: Faster double-lumen tube intubation with the videolaryngoscope than with a standard laryngoscope. Can J Anaesth. 2010; 57 (11): 980-984 PubMed Abstract | Publisher Full Text | Reference Source

7. Hsu HT, Chou SH, Wu PJ, Tseng KY, et al.: Comparison of the GlideScope ${ }^{\circledR}$ videolaryngoscope and the Macintosh laryngoscope for double-lumen tube intubation. Anaesthesia. 2012; 67 (4): 411-415 PubMed Abstract | Publisher Full Text | Reference Source 8. Wojtczak JA: Should videolaryngoscopy be used routinely during all elective intubations?. Minerva Anestesiol. 2012; 78 (9): 1076-1077 PubMed Abstract | Reference Source

9. Xue FS, Yang QY, He N, Xu YC: The modified ventilating tube changer to facilitate tracheal intubation using the GlideScope in patients with a limited mouth opening.Br J Anaesth. 2008; 101 (1): 126-127 PubMed Abstract | Publisher Full Text | Reference Source

10. Xue FS, Zhang GH, Liu J, Li XY, et al.: The clinical assessment of Glidescope in orotracheal intubation under general anesthesia.Minerva Anestesiol. 2007; 73 (9): 451-457 PubMed Abstract | Reference Source

11. Panacek EA, Laurin EG, Bair AE: Fracture of a GlideScope $®$ Cobalt GVL $®$ Stat disposable blade during an emergency intubation.J Emerg Med. 2012; 42 (6): 125-128 PubMed Abstract | Publisher Full Text | Reference Source

Competing Interests: None declared 
Reviewer Report 21 July 2014

\section{https://doi.org/10.5256/f1000research.5142.r5495}

(C) 2014 Koichi M. This is an open access peer review report distributed under the terms of the Creative Commons Attribution License, which permits unrestricted use, distribution, and reproduction in any medium, provided the original work is properly cited.

\section{Maruyama Koichi}

Department of Anesthesiology, Teikyo University, Kawasaki, Japan

Thank you very much for your new version. In the revised version, I can confirm the author's great job for presenting detailed information about the patient's safety.

Competing Interests: No competing interests were disclosed.

I confirm that I have read this submission and believe that I have an appropriate level of expertise to confirm that it is of an acceptable scientific standard.

Reader Comment 21 Jul 2014

Mohamed El Tahan, Dammam University, Saudi Arabia

Thank you so much for your efforts to improve our report.

Competing Interests: None declared

\section{Version 1}

Reviewer Report 07 July 2014

https://doi.org/10.5256/f1000research.4793.r5161

(C) 2014 Healy D. This is an open access peer review report distributed under the terms of the Creative Commons Attribution License, which permits unrestricted use, distribution, and reproduction in any medium, provided the original work is properly cited.

\section{David Healy}

Department of Anesthesiology, University of Michigan, Ann Arbor, MI, USA

Thank you for the opportunity to review this manuscript. The manuscript describes a single case report of the use of a video laryngoscope (King Vision non-channeled blade) to facilitate successful 
endobronchial intubation with a double lumen tube in an obese patients with respiratory comorbidity. The manuscript then discusses the characteristics of this particular videolayngoscope which the authors feel may lead to an improvement in success.

This case report is well written and adequately describes this challenging clinical scenario and airway management.

\section{Technical issues:}

1. There is no documentation of attempt to perform bag-mask ventilation during the case. There is no discussion of why this was not attempted or of its importance in the overall airway management of this patient. My view is the ability to perform adequate bag mask ventilation may improve the patient's oxygenation and safety during the intubation attempts; especially it they were less straightforward than that described in this manuscript.

2. There was no attempt at direct laryngoscopy recorded. The actual difficulty of this patient's airway remains unknown (e.g. She may have been easily ventilated with a bag mask and a grade I view at laryngoscopy with good positioning). She remains "at higher risk of difficulty" but the reality remains unknown.

\section{Content issues:}

1. I think the manuscript would benefit from a description of the other option of intubating a patient with a true difficult airway and significant pulmonary compromise: i.e. place a single lumen tube to improve oxygenation and ventilation, then exchange over an airway exchange catheter (Cook).

2. I think the comment on fluid choice is unnecessary.

3. Consider removing the phrase "Channeled VLs have many advantages over those with angulated blades, such as the GlideScope" - not true, and not referenced as so. Perhaps better described as "different advantages and limitations"

4. Consider removing the phrase "Previous studies.....more effective for DLT" - the references do not back up the link between an improved view and "potential successful intubation". This comment can falsely reinforce the idea that view (on VL) equates to success.

5. I appreciate their relatively conservative summary statement at the articles conclusion - and the series of steps to achieve successful intubation.

Competing Interests: No competing interests were disclosed.

I confirm that I have read this submission and believe that I have an appropriate level of expertise to confirm that it is of an acceptable scientific standard, however I have significant reservations, as outlined above. 
Reader Comment 13 Jul 2014

Mohamed El Tahan, Dammam University, Saudi Arabia

We read with interest the important comments of Dr. David Healy, Department of Anesthesiology, University of Michigan, Ann Arbor, MI, USA. Here are our responses to his comments:

\section{Technical Issues:}

1. Dr. Healy: "There is no documentation of attempt to perform bag-mask ventilation during the case. There is no discussion of why this was not attempted or of its importance in the overall airway management of this patient. My view is the ability to perform adequate bag mask ventilation may improve the patient's oxygenation and safety during the intubation attempts; especially it they were less straightforward than that described in this manuscript."

Authors: We mentioned that "After positioning of the patient on the operating table in a head-up position, anesthesia was induced using a target-controlled infusion (TCI) of sufentanil with a target effect site concentration (Ce) of $0.1 \mathrm{ng} / \mathrm{mL}$, in conjunction with $8 \%$ sevoflurane in oxygen delivered by mask ventilation.". Thus mask ventilation was used during induction with pressure-support ventilation of $15 \mathrm{~cm} \mathrm{H}_{2} \mathrm{O}$ and continued until the time laryngoscopy. We think that is unclear to the readers so we rewrote them again. We addressed that in the Case Description Section in the V2 of our report.

2. Dr. Healy: "There was no attempt at direct laryngoscopy recorded. The actual difficulty of this patient's airway remains unknown (e.g. she may have been easily ventilated with a bag mask and a grade I view at laryngoscopy with good positioning). She remains "at higher risk of difficulty" but the reality remains unknown."

Authors: We chose not to attempt direct laryngoscopy prior to the use of the King Vision $^{\mathrm{TM}}$ VL. First, the patient had three predictors of an anticipated difficult airway, including a BMI of $41.7 \mathrm{~kg} / \mathrm{m}^{2}$, a short thyromental distance and limited mouth opening. Second we were concerned about the possibility of hypoxemia if the duration of laryngoscopy and intubation was lengthened with a prior assessment of the airway using direct laryngoscopy. Note that the initial laryngoscopy using the King Vision ${ }^{\mathrm{TM}}$ VL revealed a Cormack-Lehane class II view, suggesting that the Cormack-Lehane class with direct laryngoscopy would be higher if this was used for an initial assessment. We thus felt that prior assessment of the airway using direct laryngoscopy would not be expected to change the adopted plan and would confer little benefit. Finally, note that the recent ASA Guidelines for Management of the Difficult Airway do not suggest a prior assessment using direct laryngoscopy. The guidelines also suggest the use of $V L$ as a choice for tracheal intubation in the nonemergent pathway where ventilation is adequate.

\section{Content Issues:}

1. Dr. Healy: "I think the manuscript would benefit from a description of the other option of intubating a patient with a true difficult airway and significant pulmonary compromise: i.e. place a single lumen tube to improve oxygenation and ventilation, 
then exchange over an airway exchange catheter (Cook)."

Authors: We have addressed this in the V2 in the Case Description as follows; Backup plans were revised involving the insertion of the left DLT over a placed Eschmann tracheal tube introducer (Smiths-Medical International Ltd, Hythe, Kent, UK), ), and using a King Vision ${ }^{\mathrm{TM}} \mathrm{VL}$, an Arndt's endobronchial blocker placed through a SLT.

2. Dr. Healy:"I think the comment on fluid choice is unnecessary."

Authors: We deleted it from the Case Description in the V2.

3. Dr. Healy: "Consider removing the phrase "Channeled VLs have many advantages over those with angulated blades, such as the GlideScope" - not true, and not referenced as so. Perhaps better described as "different advantages and limitations"

Authors': Unfortunately, it is "true" as Savoldelli et al (Reference no. 11 in the main text) have reported that time taken to position the endotracheal tube was shorter for the Airtraq (channelled VL) when compared with the Glidescope and McGrath (nonchannelled VL). We amended the citation of that reference to be earlier.

4. Dr. Healy: "Consider removing the phrase "Previous studies.....more effective for DLT" - the references do not back up the link between an improved view and "potential successful intubation". This comment can falsely reinforce the idea that view (on VL) equates to success.'

Authors: The confusing sentence ", making it potentially more effective for DLT placement" has been removed.

5. Dr. Healy: "I appreciate their relatively conservative summary statement at the articles conclusion - and the series of steps to achieve successful intubation.

Authors: Thank you so much.

\section{References:}

1. Enterlein G; Byhahn C. Practice guidelines for management of the difficult airway: update by the American Society of Anesthesiologists task force. Anaesthesist, 2013; 62(10): 832-5.

2. Apfelbaum JL, Hagberg CA, Caplan RA, et al. Practice guidelines for management of the difficult airway: an updated report by the American Society of Anesthesiologists Task Force on Management of the Difficult Airway. Anesthesiology 2013;118(2): 25170

Competing Interests: None declared. 
Reviewer Report 30 June 2014

https://doi.org/10.5256/f1000research.4793.r5164

(c) 2014 Koichi M. This is an open access peer review report distributed under the terms of the Creative Commons Attribution License, which permits unrestricted use, distribution, and reproduction in any medium, provided the original work is properly cited.

\section{Maruyama Koichi}

Department of Anesthesiology, Teikyo University, Kawasaki, Japan

Thank you for your case report demonstrating the effectiveness of non-channeled King Vision for DLT intubation in a morbidly obese patient with predicted difficult airway and severely restrictive pulmonary dysfunction.

I have a few comments and questions:

Was the patient pre-oxygenated enough? Oxygen at $3 \mathrm{~L} / \mathrm{min}$ via a nasal cannula could provide an approximate $\mathrm{FiO}_{2}$ of only 0.33 . How long did it take from the cessation of mask ventilation until the resumption of the mechanical ventilation after intubation? In addition, could you tell me the lowest $\mathrm{SpO}_{2}$ during intubation?

As you mentioned, the patient was easily expected to be exposed to the risk of severe hypoxia due to the morbid obesity and the comorbid pulmonary disease, as well as the predicted difficult airway. Furthermore, the time elapsed for intubation with the nonchanneled King Vision would be longer than that with the conventional laryngoscopy or that with the channeled King Vision (Akihisa et al., 2014).

The effectiveness of the non-channeled King Vision for DLT intubation was well described in this report. To clear the ethical issue, however, please provide the detailed information about the patient's safety.

Competing Interests: No competing interests were disclosed.

I confirm that I have read this submission and believe that I have an appropriate level of expertise to confirm that it is of an acceptable scientific standard, however I have significant reservations, as outlined above.

Reader Comment 05 Jul 2014

Mohamed El Tahan, Dammam University, Saudi Arabia

We read with interest the important comments of Dr. Maruyama Koichi, Teikyo University, Japan. Here are our responses to his comments:

Dr. Koichi: Was the patient pre-oxygenated enough? Oxygen at $3 \mathrm{~L} / \mathrm{min}$ via a nasal cannula could provide an approximate FiO2 of only 0.33 .

Authors: The initial delivered oxygen at $3 \mathrm{~L} / \mathrm{min}$ via nasal cannulae was followed by routine preoxygenation with $100 \%$ oxygen in conjunction with $8 \%$ sevoflurane by 
mask ventilation. This lasted about $8 \mathrm{~min}$.

Dr. Koichi: How long did it take from the cessation of mask ventilation until the resumption of the mechanical ventilation after intubation? In addition, could you tell me the lowest $\mathrm{SpO}_{2}$ during intubation?

Authors: The time taken from the cessation of mask ventilation until resumption of the mechanical ventilation after intubation lasted about 90 s. The lowest $\mathrm{SpO}_{2}$ during intubation was $95 \%$.

Dr. Koichi: As you mentioned, the patient was easily expected to be exposed to the risk of severe hypoxia due to the morbid obesity and the comorbid pulmonary disease, as well as the predicted difficult airway. Furthermore, the time elapsed for intubation with the non-channeled King Vision would be longer than that with the conventional laryngoscopy or that with the channeled King Vision (Akihisa et al., 2014)

Authors: First, as mentioned above, the apneic time lasted for only 90 seconds, with the lowest $\mathrm{SpO}_{2}$ being $95 \%$. Second, we read with interest your cited study (Akihisa et al., 2014). In this study the authors reported longer intubation time with the use of the non-channelled King Vision laryngoscope compared with the conventional Macintosh or with the channelled King Vision video laryngoscopes $(p<0.001)$. However, the results of that particular study cannot readily be applied to the present case report because the operators were non-experienced nurses who had never previously performed tracheal intubation (rather than anesthesiologists with over 10 years of experience, as in the present report). In addition, the Akihisa study was done on manikins with simulated normal airways rather than patients with a difficult airway, and it tested the efficacy of the tested devices using a single lumen tube rather than the larger double lumen tube.

Dr. Koichi: The effectiveness of the non-channeled King Vision for DLT intubation was well described in this report. To clear the ethical issue, however, please provide the detailed information about the patient's safety.

Authors: First, as we mentioned, multidisciplinary discussions involving a cardiothoracic surgeon, a pulmonologist, anesthesiologists and the family of the patients took place, emphasizing the possibility of acute pulmonary compromise during tracheal intubation and surgery. Second, a stepwise plan was formulated as described. Third, standard monitoring, preoxygenation, and anesthetic technique were carried out. Fourth, the signed informed consent both for the perioperative management and for the publication of the patient's data were obtained.

Competing Interests: None declared 
The benefits of publishing with F1000Research:

- Your article is published within days, with no editorial bias

- You can publish traditional articles, null/negative results, case reports, data notes and more

- The peer review process is transparent and collaborative

- Your article is indexed in PubMed after passing peer review

- Dedicated customer support at every stage

For pre-submission enquiries, contact research@f1000.com 